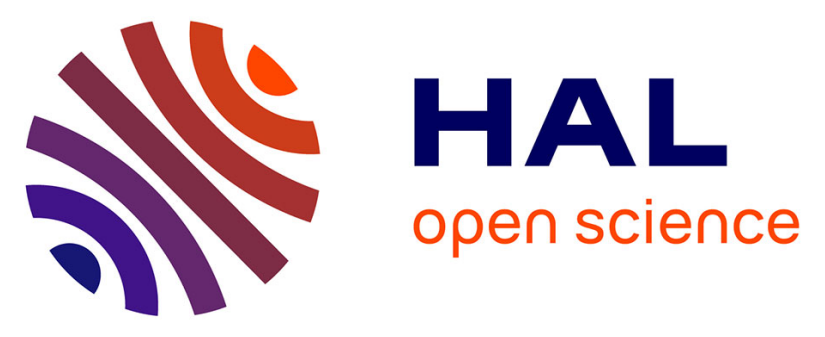

\title{
Treatment of Complex Aortic Aneurysms Using Combination of Renal and Visceral Bypass and Fenestrated/Branched Stent Grafts
}

Ambroise Duprey, Sabrina Ben Ahmed, Nellie Della Schiava, Patrick Feugier, Eugenio Rosset, Jean-Pierre Favre, Bertrand Chavent, Jean-Noël Albertini

\section{To cite this version:}

Ambroise Duprey, Sabrina Ben Ahmed, Nellie Della Schiava, Patrick Feugier, Eugenio Rosset, et al.. Treatment of Complex Aortic Aneurysms Using Combination of Renal and Visceral Bypass and Fenestrated/Branched Stent Grafts. Annals of Vascular Surgery, 2019, 57, pp.91 - 97. 10.1016/j.avsg.2018.09.025 . hal-03486090

\section{HAL Id: hal-03486090 https://hal.science/hal-03486090}

Submitted on 20 Dec 2021

HAL is a multi-disciplinary open access archive for the deposit and dissemination of scientific research documents, whether they are published or not. The documents may come from teaching and research institutions in France or abroad, or from public or private research centers.
L'archive ouverte pluridisciplinaire HAL, est destinée au dépôt et à la diffusion de documents scientifiques de niveau recherche, publiés ou non, émanant des établissements d'enseignement et de recherche français ou étrangers, des laboratoires publics ou privés.

\section{(ㄷ)(1) $\$$}

Distributed under a Creative Commons Attribution - NonCommerciall 4.0 International 
1 TREATMENT OF COMPLEX AORTIC ANEURYSMS USING COMBINATION OF

2 RENAL AND VISCERAL BYPASS AND FENESTRATED/BRANCHED STENT-

3 GRAFTS.

4 Ambroise Duprey ${ }^{\mathbf{a}}$, Sabrina Ben Ahmed ${ }^{\mathbf{b}}$, Nellie Della Schiava ${ }^{\mathrm{c}}$, Patrick Feugier,

$5 \quad$ Eugenio Rosset $^{\text {b }}$, Jean-Pierre Favre ${ }^{\mathrm{a}}$, Bertrand Chavent ${ }^{\mathrm{a}}$, Jean-Noël Albertini ${ }^{\mathrm{a}}$

$6 \quad{ }^{a}$ Department of Cardiovascular Surgery, University Hospital of Saint-Etienne, France

$7 \quad{ }^{b}$ Department of Vascular Surgery, University Hospital of Clermont-Ferrand, France

$8{ }^{\mathrm{c}}$ Department of Vascular and Endovascular Surgery, University Hospital of Lyon, France

9 Corresponding author:

10

11
Ambroise Duprey

Service de Chirurgie Cardiovasculaire

CHU de Saint-Etienne, 42055 Saint-Etienne, cedex 2

Phone : +33477828243

Fax : +33477828453

ambroise.duprey@gmail.com 


\section{Abstract}

\section{Purpose}

The purpose of this study was to report our experience of treatment of aortic aneurysms using combination of renal and visceral arteries bypass and fenestrated/branched stentgraft in various complex anatomical situations.

\section{Methods}

Between November 2005 and March 2017, 10 patients underwent a hybrid strategy combining bypasses for renal and/or visceral arteries and custom-made fenestrated/branched stent-grafts. Two patients had abdominal aortic aneurysm (1 juxtarenal and 1 suprarenal) and 8 patients had thoracoabdominal aortic aneurysm (1 type I, 2 type II including one dissection, 2 type III, 1 type IV and 2 type V). In total, 37 renal and visceral arteries were targeted, 23 of which using fenestration or branch and 14 using bypass (11 to renal artery and 3 to coeliac trunk).

\section{Results}

Technical success was $100 \%$ and no patient died during a mean follow-up of $24.3 \pm 21$ months. Six patients had 7 postoperative complications after bypass surgery and 3 patients had 3 complications after FEVAR/BEVAR procedure. Seven reinterventions were performed in 3 patients. No occlusion of target vessels occurred. Renal function was stable during follow-up in all patients but one who developed end-stage renal failure requiring permanent dialysis. On last follow-up CT-scan, aneurysm diameter decreased for 6 patients, was stable for 3 patients and increased for one patient, in which persistent type 2 endoleak was observed. Aneurysm exclusion was complete in the remaining 9 patients.

\section{Conclusion}


39 Combination of FEVAR/BEVAR procedures with renal and/or visceral artery bypass in 40 patients with complex aortic aneurysms is feasible with acceptable results. Morbidity 41 associated with bypass surgery has to be carefully balanced with the risk of catheterism 42 difficulties in the setting of adverse anatomical features of the visceral/renal arteries or the 43 aorta. 


\section{Introduction}

Fenestrated and branched stent-grafts have become a widely used alternative for the treatment of juxtarenal (JR), suprarenal (SR) and thoraco-abdominal aortic aneurysms (TAA) in patients at high risk for conventional open repair [1-4]. Encouraging short-term results with custommade devices have been reported in patients with complex aorto-iliac anatomy and multiple comorbidities. However, a number of adverse morphological features may increase technical difficulties during fenestrated or branched endovascular aneurysm repair (FEVAR/BEVAR), or may preclude the ability of manufacturing suitable custom-made fenestrated/branched stent-grafts [5,6]. Lerussi et al. have described a combination of a right hepato-renal artery bypass and a fenestrated stent-graft in the setting of a juxtarenal aneurysm, with very close origins of right renal and superior mesenteric (SMA) arteries, precluding the construction of fenestrations for both vessels [7]. The aim of the present study was to report our experience of treatment of aortic aneurysms using combination of renal and visceral arteries bypass and fenestrated/branched stentgraft in various complex anatomical situations. 


\section{Methods}

Between November 2005 and March 2017, 199 patients underwent FEVAR and/or BEVAR for complex aortic aneurysms at three university regional vascular centers. In 10 patients, a hybrid strategy combining bypasses for renal and/or visceral arteries and custom-made fenestrated/branched stent-grafts was chosen.

\subsection{Patients}

Two patients had abdominal aortic aneurysm (1 JR and 1 SR) and 8 patients had TAA (1 type I, 2 type II including one dissection, 2 type III, 1 type IV and 2 type V). Patients and aneurysms characteristics are reported in Table 1. In our centers, FEVAR/BEVAR treatment is proposed for JR and SR aneurysms in high surgical risk patients and as a fist-line option for TAA in patients at high and standard surgical risk.

\subsection{Stent-grafts and procedures}

In total, 37 renal and visceral arteries were targeted, 23 of which using fenestration or branch and 14 using bypass. Details of bypass/stentgraft combination for each target vessel are reported in Table 2 and indications for renal/visceral bypass and type of revascularization are reported in Table 3. Early renal artery bifurcation was defined as a trunk shorter than $10 \mathrm{~mm}$. In the 2 patients where renal bypass was performed because of polar arteries, one had right kidney vascularized by two $4 \mathrm{~mm}$ diameter polar arteries and the second patient had main trunk and polar artery diameters of 4 and $3.5 \mathrm{~mm}$, respectively. In each case, both polar arteries were bypassed. Three patients who underwent renal bypass had solitary kidney. Bypass and stent-graft configurations for two patients are depicted in Figures 1 and 2.

All stent-grafts were custom-made devices (Cook Medical ${ }^{\circledR}$, Bloomington, USA). Staged procedures were performed in all patients: 7 patients had 2 procedures (visceral/renal bypass 

stentgraft with or without supra-aortic trunk debranching, and FEVAR/BEVAR procedure)

83 and one had 4 procedures (debranching of supra-aortic trunk, visceral/renal bypass, thoracic stentgraft and FEVAR). In patients with type II or type III TAA, implantation of thoracic

and FEVAR/BEVAR procedure), 2 patients had 3 procedures (visceral/renal bypass, thoracic stentgrafts was performed as a separate procedure in order to reduce the risk of spinal cord ischemia (SCI).

All procedures were performed under general anesthesia in a conventional vascular operating theatre using portable C-arm (Siemens Avantic or Phillips Veradius). Spinal fluid drainage was performed in all patients with TAA. 


\section{Results}

\subsection{Results of renal/visceral bypass procedures}

No patient died during the postoperative period. Six patients had 7 postoperative complications (one patient underwent surgical revision for hemorrhage following hepato-renal bypass, one patient underwent exploratory laparotomy for intestinal obstruction syndrome with fever, one had groin infection requiring intervention, three had transient serum creatinine rise following renal artery bypass without dialysis and one had pulmonary embolism). Seven patients were discharged home before FEVAR/BEVAR procedure with a mean hospital stay of $14 \pm 6$ days (range $9-21$ days) including the pre-operative admission day.

\subsection{Results of FEVAR/ BEVAR procedures}

Technical success of FEVAR/BEVAR procedures was achieved in all cases. Median duration of FEVAR/BEVAR procedure was 255 min (163 - $383 \mathrm{~min})$. Median contrast load was 100 $\mathrm{ml}(50-200 \mathrm{ml})$, median radiation exposure time and median dose area product were $59 \mathrm{~min}$ $(22-129 \mathrm{~min})$ and $11,3 \mathrm{~Gy} \cdot \mathrm{cm}^{2}\left(9-22,3 \mathrm{~Gy} \cdot \mathrm{cm}^{2}\right)$ respectively.

No patient died during the postoperative period. Three patients had 3 complications after FEVAR/BEVAR procedure (one iliac limb stenting for kinking and two transient serum creatinine rises including one transient hemodialysis).

In total, 6 patients had 10 complications during postoperative course.

Mean delay between first outpatient clinic and FEVAR/BEVAR procedure was $8.6 \pm 3.6$ months (range 3 - 14 months). Mean delay between bypass and FEVAR/BEVAR procedure was $1.3 \pm 0.8$ months (range $0.4-2.9$ months).

Mean hospital stay following FEVAR/BEVAR procedure was $9 \pm 5$ days (range $5-20$ days). 
113 Post-operative CT-scan was performed in all patients. Proximal endoleak from incomplete

114 sealing of subclavian occluder was seen in the patient who presented with a type II dissecting

115 TAA. The same patient had a distal type 1 endoleak from a reentry tear located at the level of 116 the right iliac bifurcation. Two patients had type 2 endoleak. Renal and visceral arteries were 117 all patent.

\subsection{Mid-term outcomes}

During a mean follow-up of $24.3 \pm 21$ months (range $3-70$ months) following FEVAR/BEVAR procedure, no patients died. Seven reinterventions were performed in 3 patients. One patient treated for a type III TAA presented at 38 months with a ruptured thoracic aneurysm from proximal type 1 endoleak. Emergent placement of a thoracic stentgraft sealed the endoleak successfully. CT-scan showed aneurysmal evolution of ascending aorta and arch. Conventional replacement of the ascending aorta and the arch was performed one month later with uneventful postoperative course.

A second patient treated for a type III TAA developed stenosis of proximal part of ilio-renohepatic saphenous bypass at 4 months. Stenting was performed, but CT-scan at 10 months showed thrombosis of the ilio-renal segment of the saphenous bypass. Meanwhile, renohepatic segment was patent and renal artery was still perfused by reverse flow from SMA collaterals (coeliac trunk was occluded by stent-graft). However, this resulted in severe renovascular hypertension requiring 5 antihypertensive drugs. This patient presented at 37 months with type 3 endoleak from disconnection of left renal artery stent which was treated successfully with additional stenting.

A third patient treated for a type II dissecting aneurysm was diagnosed at 6 months with persistent endoleak from incomplete sealing of a subclavian occluder. Complete occlusion 
was achieved using plug and coils. At 8 months, this patient underwent iliac limb extension for a persistent distal type 1 endoleak from a re-entry tear. CT-scan at 17 months showed enlargement of the aneurysm sac and large endoleak in the false lumen which was suspected to arise from coeliac trunk and SMA fenestrations. Additional stenting of SMA and coeliac trunk was performed. Last CT-scan showed stability of aneurysm diameter and the persistence of endoleak which was categorized as a type 2 .

During follow-up, no occlusion of target vessels was documented. One patient already mentioned above had partial thrombosis of the iliac part of a saphenous ilio-reno-hepatic bypass. Another patient with reno-hepatic bypass associated with right renal artery branch was diagnosed at 6 months with thrombosis of the right renal branch. Again, right renal artery and reno-hepatic bypass remained patent thanks to collaterals arising from the SMA (coeliac trunk was occluded by stent-graft).

Renal function was stable during follow-up in all patients but one who developed end-stage renal failure requiring permanent dialysis. This patient had solitary kidney and preoperative severe chronic renal failure (CKD-EPI clearance of $\left.17 \mathrm{ml} / \mathrm{min} / 1.73 \mathrm{~m}^{2}\right)$.

On last follow-up CT-scan, aneurysm diameter decreased for 6 patients from a mean of $65 \pm 6$ $\mathrm{mm}$ to $45 \pm 10 \mathrm{~mm}$, was stable for 3 patients and increased for one patient from 90 to 100 $\mathrm{mm}$, in which persistent type 2 endoleak was observed. Aneurysm exclusion was complete in the remaining 9 patients. 


\section{Discussion}

This study reports our experience of a hybrid strategy combining bypass to the renal and/or visceral arteries and FEVAR/BEVAR in the treatment of complex aortic aneurysms, in patients unfit for open repair and for which difficult anatomy precluded a total endovascular approach. During the last decade, early and mid-term outcomes following FEVAR/BEVAR have improved thanks to advances in preoperative planning, patient selection, implantation technique and perioperative care. FEVAR/BEVAR has become a first-line treatment option for patients at high risk for open repair. FEVAR indications have even been extended in some centers to standard surgical-risk patients with JR and SR abdominal aortic aneurysms [2]. Recent literature data support the benefit of endovascular approach in complex aortic aneurysms compared to conventional open surgery and full hybrid procedures (complete renal and visceral bypass revascularization combined with standard stent-graft) in terms of perioperative mortality and major complication rates $[8,9]$.

Most recent FEVAR/BEVAR series have shown high technical success rates above 95\% $[1,2]$. Technical success of target vessel stent implantation relies to a large extent on patient selection and preoperative planning. In some cases, preoperative CT-scan shows unfavorable anatomy associated with possible technical difficulties that may increase procedure time and lead to failure of renal/visceral stenting. An inverse correlation between procedure time and mortality [10] or the incidence of SCI [4] has been demonstrated. The use of bypass procedures for those complex arteries may simplify the FEVAR/BEVAR procedure, and thereby decrease the extent of catheter manipulation (with potential reduction of peripheral emboli) and procedure time.

With regards to renal artery anatomy, Mendes et al. have reported that, among 520 patients treated for complex aortic aneurysm (222 JR, 241 SR and 57 type IV TAA), 92 (18\%) had 
unsuitable anatomy for FEVAR/BEVAR [5]. Unsuitability criteria for endovascular incorporation of renal artery were: early bifurcation (defined as length of renal artery trunk < $13 \mathrm{~mm}$ ), diameter $<4 \mathrm{~mm}$ and accessory renal artery requiring sacrifice of $>40 \%$ of volume of a single kidney or $>25 \%$ of two kidneys. Occurrence of accessory renal arteries is not rare and has been estimated to affect one third of the population [11,12]. Renal artery angulation has also been associated with increased canulation time [6], and in Mendes series, excessive downward angulation was observed in $24 \%$ of the patients [5]. In our report, anatomic difficulty involved renal arteries in 11 out of 14 cases of bypass revascularization. In 8 of these 11 patients, bypass indication was related to adverse anatomical feature of the renal artery (Table 3). In the three remaining cases, one had type II TAA following type B aortic dissection and right renal artery originating from the false lumen, and in the two others, indication for renal bypass was a tight angulation of the aorta at the level of renal arteries. We considered that this anatomical feature would have carried a high risk of misplacement of the renal fenestrations, with potential failure to canulate the renal arteries. A more compliant stent-graft, like the Vascutek ${ }^{\circledR}$ Anaconda fenestrated custom-made device was considered, but not possible as reimbursement by our healthcare system was lacking.

Target vessel incorporation failures are most often related to renal arteries. Nevertheless, Verhoeven et al. [3] and Eagleton et al [13] reported coeliac trunk canulation failure in one and 13 cases, respectively. In the latter series, failure of coeliac trunk canulation was related in 12 cases to a high-grade stenosis $(>95 \%)$ or an occlusion. In our series, 3 patients underwent bypass to the coeliac trunk because of a high-grade stenosis. Two of these patients presented with indication of right renal artery bypass revascularization, and therefore we decided to take advantage of the laparotomy to undertake concomitant bypass to the coeliac trunk. The third patient presented with type III TAA and tight stenosis of coeliac trunk. Design of stent-graft was 2 branches for superior mesenteric artery and right renal artery and 
one fenestration for left renal artery. As the procedure was expected to be challenging, we decided to undertake prior bypass revascularization to the coeliac trunk in order to minimize procedure time.

In the present report, the choice of renal/visceral bypass revascularization was intended to insure target vessel patency as well as shorter FEVAR/BEVAR procedure duration. This strategy has already been described in a single report by Lerussi et al., where saphenous vein hepato-renal bypass was performed prior to the endovascular procedure [7]. In this patient, right renal artery and SMA origins were too close to each other, and this precluded the construction of fenestrations for both vessels. Recent publications advocate staging of multiple procedures, mostly as a strategy to reduce the risk of SCI $[1,4,14,15]$. Following this strategy, all patients in the present series underwent bypass surgery prior to FEVAR/BEVAR. One major drawback of staging is that the patient is exposed to the risk of aneurysm rupture between both procedures. However, in our series, bypass surgery was always performed during the stent-graft manufacturing period. Finally, it appears that visceral/renal bypass did not significantly delay the FEVAR/BEVAR procedure.

In our series, 10 complications occurred in 6 patients. Most of the complications (seven out of ten) occurred following bypass surgery. Reported morbidity following extra-anatomic renal bypass is around $10 \%$ [16]. This higher morbidity rate may be explained by the fact that all patients were at high risk for open surgery. On the other hand, complication rate following FEVAR/BEVAR procedure was comparable to previous reports [1-4].

In our series, mean hospital stay was 9 days following FEVAR/BEVAR procedure. This was comparable to 7 to 10 days reported by Verhoeven et al $[2,3]$.

Seven reinterventions were needed in 3 patients, one of which related to renal bypass. This rate of reintervention is comparable to other endovascular series [1,3]. 
228 5. Conclusion

229 The present series confirms the feasibility with acceptable results of combining 230 FEVAR/BEVAR procedures with renal and/or visceral artery bypass in patients with complex

231 aortic aneurysms. The morbidity associated with these open procedures in fragile patients has 232 to be carefully balanced with the risk of catheterism difficulties in the setting of adverse 233 anatomical features of the visceral/renal arteries or the aorta.

\section{Declaration of interest}

235 None

\section{Funding}

237 This research did not receive any specific grant from funding agencies in the public, 238 commercial, or not-for-profit sectors. 


\section{References}

[1] Oderich GS, Ribeiro M, Hofer J, et al. Prospective, nonrandomized study to evaluate endovascular repair of pararenal and thoracoabdominal aortic aneurysms using fenestrated-branched endografts based on supraceliac sealing zones. J Vasc Surg. 2017;65(5):1249-1259.e10.

[2] Verhoeven ELG, Katsargyris A, Oikonomou K, et al. Fenestrated Endovascular Aortic Aneurysm Repair as a First Line Treatment Option to Treat Short Necked, Juxtarenal, and Suprarenal Aneurysms. Eur J Vasc Endovasc Surg. 2016;51(6):775-81.

[3] Verhoeven ELG, Katsargyris A, Bekkema F, et al. Editor's Choice - Ten-year Experience with Endovascular Repair of Thoracoabdominal Aortic Aneurysms: Results from 166 Consecutive Patients. Eur J Vasc Endovasc Surg. 2015;49(5):524-31.

[4] Maurel B, Delclaux N, Sobocinski J, et al. Editor's Choice - The Impact of Early Pelvic and Lower Limb Reperfusion and Attentive Peri-operative Management on the Incidence of Spinal Cord Ischemia During Thoracoabdominal Aortic Aneurysm Endovascular Repair. Eur J Vasc Endovasc Surg. 2015;49(3):248-54.

[5] Mendes BC, Oderich GS, Reis de Souza L, et al. Implications of renal artery anatomy for endovascular repair using fenestrated, branched, or parallel stent graft techniques. J Vasc Surg. 2016;63(5):1163-1169.e1.

[6] Ullery BW, Chandra V, Dalman RL, et al. Impact of Renal Artery Angulation on Procedure Efficiency During Fenestrated and Snorkel/Chimney Endovascular Aneurysm Repair. J Endovasc Ther. 2015;22(4):594-602. 
[7] Lerussi G, O’Brien N, Sessa C, et al. Hepatorenal Bypass Allowing Fenestrated Endovascular Repair of Juxtarenal Abdominal Aortic Aneurysm: A Case Report. Eur J Vasc Endovasc Surg. 2010;39(3):305-7.

[8] Coselli JS, LeMaire SA, Preventza O, et al. Outcomes of 3309 thoracoabdominal aortic aneurysm repairs. J Thorac Cardiovasc Surg. 2016;151(5):1323-38.

[9] Rosset E, Ben Ahmed S, Galvaing G, et al. Editor's Choice - Hybrid Treatment of Thoracic, Thoracoabdominal, and Abdominal Aortic Aneurysms: A Multicenter Retrospective Study. Eur J Vasc Endovasc Surg. 2014;47(5):470-8.

[10] Marzelle J, Presles E, Becquemin JP, et al. Results and factors affecting early outcome of fenestrated and/or branched stent grafts for aortic aneurysms: a multicenter prospective study. Ann Surg. 2015;261(1):197-206.

[11] Pollak R, Prusak BF, Mozes MF. Anatomic abnormalities of cadaver kidneys procured for purposes of transplantation. Am Surg. 1986;52(5):233-5.

[12] Türkvatan A, Özdemir M, Cumhur T, et al. Multidetector CT angiography of renal vasculature: normal anatomy and variants. Eur Radiol. 2009;19(1):236-44.

[13] Eagleton MJ, Follansbee M, Wolski K, et al. Fenestrated and branched endovascular aneurysm repair outcomes for type II and III thoracoabdominal aortic aneurysms. J Vasc Surg. 2016;63(4):930-42.

[14] Bischoff MS, Scheumann J, Brenner RM, et al. Staged Approach Prevents Spinal Cord Injury in Hybrid Surgical-Endovascular Thoracoabdominal Aortic Aneurysm Repair: An Experimental Model. Ann Thorac Surg. 2011;92(1):138-46. 
281 [15] O'Callaghan A, Mastracci TM, Eagleton MJ. Staged endovascular repair of

282 thoracoabdominal aortic aneurysms limits incidence and severity of spinal cord ischemia.

283 J Vasc Surg. 2015;61(2):347-354.e1.

284 [16] Cambria RP, Brewster DC, L'Italien GJ, et al. The durability of different

285 reconstructive techniques for atherosclerotic renal artery disease. J Vasc Surg.

$286 \quad 1994 ; 20(1): 76-87$. 


\begin{tabular}{|c|c|}
\hline Variables & $N=10$ \\
\hline \multicolumn{2}{|l|}{ Demographics } \\
\hline Median age (range) & 63 years $(50-76)$ \\
\hline Male sex (n) & 8 \\
\hline Comorbidities & $n$ \\
\hline Diabetes & 1 \\
\hline Smoker & 4 \\
\hline Hypertension & 10 \\
\hline Hyperlipidemia & 3 \\
\hline Coronary artery disease & 3 \\
\hline Myocardial infarction & 1 \\
\hline Congestive heart failure & 0 \\
\hline Peripheral artery disease & 0 \\
\hline Stroke/TIA & 0 \\
\hline Chronic kidney disease & 3 \\
\hline COPD & 1 \\
\hline Obesity & 2 \\
\hline Other medical history & $n$ \\
\hline Prior laparotomy & 1 \\
\hline Prior open AAA repair & 0 \\
\hline Prior EVAR & 1 \\
\hline ASA score & $n$ \\
\hline Class II & 4 \\
\hline Class III & 5 \\
\hline Class IV & 1 \\
\hline Type of aneurysm (n) & Median maximum diameter $(\mathrm{mm})$ \\
\hline $\mathrm{JR} \quad(1)$ & 65 \\
\hline SR $\quad(1)$ & 75 \\
\hline TAA I & 60 \\
\hline TAA II & $76(62-90)$ \\
\hline TAA III & $65(60-70)$ \\
\hline TAA IV (1) & 69 \\
\hline TAA V & $62(61-63)$ \\
\hline
\end{tabular}

TIA, transient ischemic attack; COPD, chronic obstructive pulmonary disease; ASA, American Society of Anesthesiologists Physical Status Classification; JR, juxtarenal aortic aneurysm; SR, suprarenal aortic aneurysm; TAA, thoracoabdominal aortic aneurysm 
Table 2. Bypass and stent-graft combination for target vessels.

\begin{tabular}{lcccc} 
Target vessel & Bypass & Fenestration & Branch & Total \\
\hline Renal artery & $\begin{array}{c}\text { 11 including } \\
7 \text { ilio-renal } \\
\text { 4 hepato-renal }\end{array}$ & 5 & 1 & 17 \\
\hline $\begin{array}{l}\text { Superior mesenteric } \\
\text { artery }\end{array}$ & 0 & 4 & 6 & 10 \\
\hline Coeliac trunk & $\begin{array}{c}\text { 3 including } \\
\text { 1 reno-hepatic } \\
\text { 2 ilio-hepatic }\end{array}$ & 3 & 4 & 10 \\
\hline Total & 14 & 12 & 11 & 37
\end{tabular}




\begin{tabular}{|c|c|c|}
\hline Target vessel & Indication (n) & Type of revascularisation (n) \\
\hline \multirow{5}{*}{ Renal artery } & $\begin{array}{l}\text { Steep anteroposterior } \\
\text { course and tight stenosis (2) }\end{array}$ & $\begin{array}{l}\text { Right hepato-renal prosthetic bypass }(1)^{S K} \\
\text { Right ilio-renal and hepatic prosthetic bypass }(1)^{*}\end{array}$ \\
\hline & Early bifurcation (4) & $\begin{array}{l}\text { Bilateral right ilio-renal prosthetic bypass }(1)^{\dagger} \\
\text { Right hepato-renal prosthetic bypass }(1) \\
\text { Right ilio-renal and hepatic saphenous vein bypass }(1)^{\ddagger} \\
\text { Bilateral right ilio-renal prosthetic bypass }(1)^{\S}\end{array}$ \\
\hline & Polar artery (2) & $\begin{array}{l}\text { Bilateral right ilio-renal prosthetic bypass }(1)^{\dagger} \\
\text { Right hepato-renal saphenous vein bypass }(1)^{S K}\end{array}$ \\
\hline & Takeoff in false lumen (1) & Right hepato-renal prosthetic bypass (1) \\
\hline & $\begin{array}{l}\text { Tight angulation of aorta at } \\
\text { the level of renal arteries } \\
\text { (2) }\end{array}$ & $\begin{array}{l}\text { Left ilio-renal prosthetic bypass }(1)^{S K} \\
\text { Bilateral right ilio-renal prosthetic bypass }(1)^{\S}\end{array}$ \\
\hline Coeliac trunk & Tight stenosis (3) & $\begin{array}{l}\text { Right reno-hepatic saphenous vein bypass (1) } \\
\text { Right ilio-renal and hepatic saphenous vein bypass }(1)^{3} \\
\text { Right ilio-renal and hepatic prosthetic bypass }(1)^{*}\end{array}$ \\
\hline
\end{tabular}


296 Figure 1. A. Schematic view of a type III TAA presenting with tight stenosis of coeliac trunk 297 and early bifurcation of right renal artery. B. Hybrid FEVAR/BEVAR strategy combining one 298 branch to the SMA, one fenestration to the left renal artery and a right ilio-renal and hepatic saphenous vein bypass. Note that saphenous vein was harvested with a native bifurcation 300 allowing for separated revascularization of both renal branches.

302 Figure 2. A. Schematic view of a type II TAA presenting with tight stenosis of coeliac trunk 303 and steep anteroposterior course and tight stenosis of right renal artery. B. Hybrid 304 FEVAR/BEVAR strategy combining one branch to the SMA, one fenestration to the left renal 305 artery, left subclavian artery reimplantation into left common carotid artery, thoracic stent306 graft and a right ilio-renal and hepatic prosthetic bypass. 
(CIllustration Médicale\&Didactique, sjacopin@illustration-medicale.com
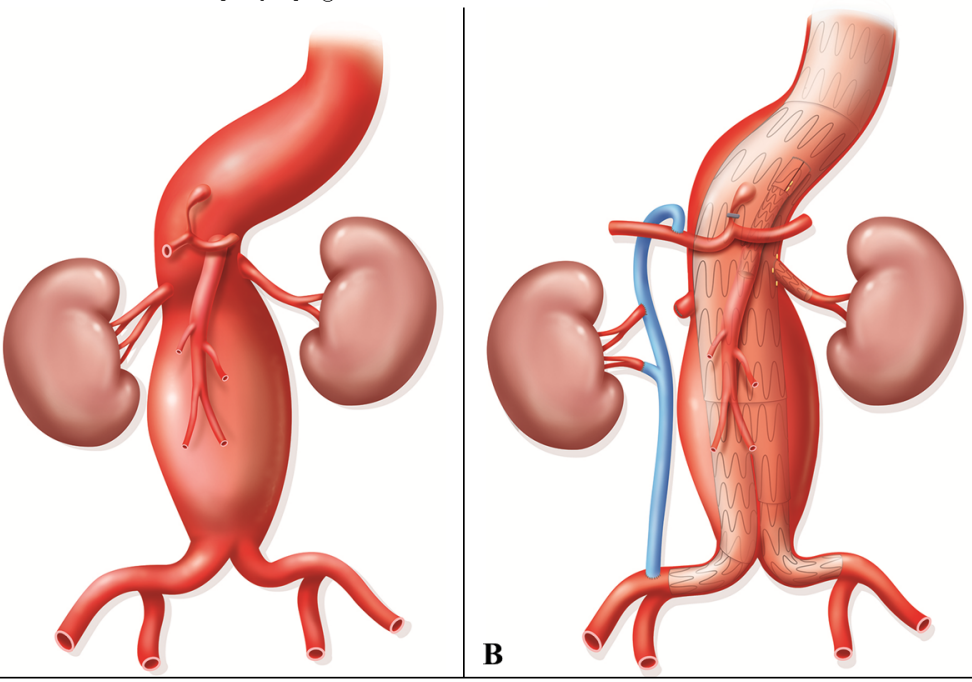
(C)Illustration Médicale\&Didactique, sjacopin@illustration-medicale.com

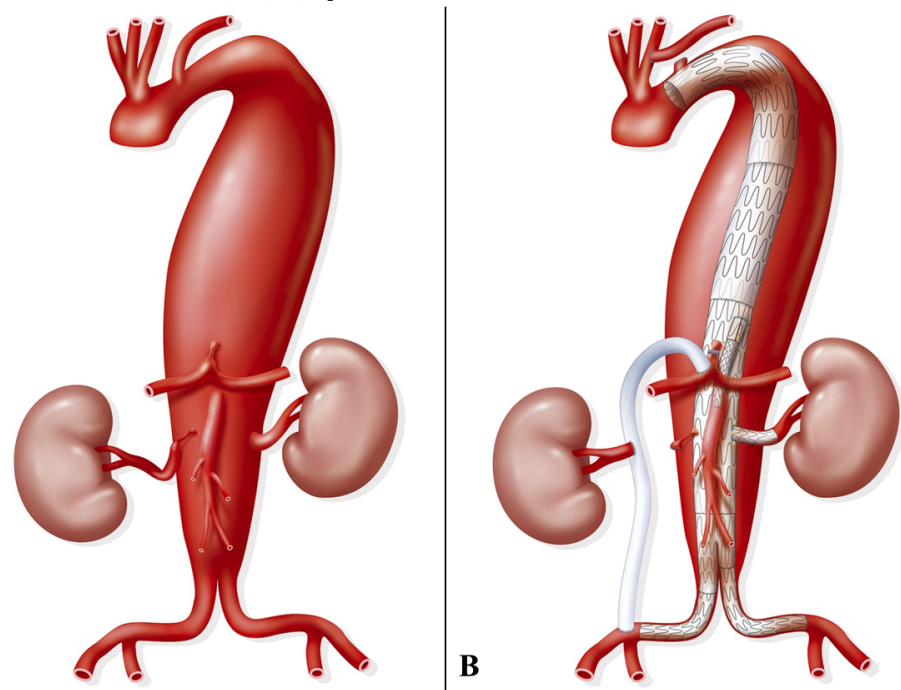


Table 1. Patients and aneurysms characteristics

\begin{tabular}{|c|c|}
\hline Variables & $N=10$ \\
\hline \multicolumn{2}{|l|}{ Demographics } \\
\hline Median age (range) & 63 years $(50-76)$ \\
\hline Male sex (n) & 8 \\
\hline Comorbidities & $n$ \\
\hline Diabetes & 1 \\
\hline Smoker & 4 \\
\hline Hypertension & 10 \\
\hline Hyperlipidemia & 3 \\
\hline Coronary artery disease & 3 \\
\hline Myocardial infarction & 1 \\
\hline Congestive heart failure & 0 \\
\hline Peripheral artery disease & 0 \\
\hline Stroke/TIA & 0 \\
\hline Chronic kidney disease & 3 \\
\hline COPD & 1 \\
\hline Obesity & 2 \\
\hline Other medical history & $n$ \\
\hline Prior laparotomy & 1 \\
\hline Prior open AAA repair & 0 \\
\hline Prior EVAR & 1 \\
\hline ASA score & $n$ \\
\hline Class II & 4 \\
\hline Class III & 5 \\
\hline Class IV & 1 \\
\hline Type of aneurysm (n) & Median maximum diameter ( $\mathrm{mm}$ ) \\
\hline JR & 65 \\
\hline SR & 75 \\
\hline TAA I & 60 \\
\hline TAA II & $76(62-90)$ \\
\hline TAA III & $65(60-70)$ \\
\hline TAA IV (1) & 69 \\
\hline TAA V (2) & $62(61-63)$ \\
\hline
\end{tabular}

TIA, transient ischemic attack; COPD, chronic obstructive pulmonary disease; ASA, American Society of Anesthesiologists Physical Status Classification; JR, juxtarenal aortic aneurysm; SR, suprarenal aortic aneurysm; TAA, thoracoabdominal aortic aneurysm 
Table 2. Bypass and stent-graft combination for target vessels.

\begin{tabular}{lcccc} 
Target vessel & Bypass & Fenestration & Branch & Total \\
\hline Renal artery & $\begin{array}{c}\text { 11 including } \\
7 \text { ilio-renal } \\
\text { 4 hepato-renal }\end{array}$ & 5 & 1 & 17 \\
\hline $\begin{array}{l}\text { Superior mesenteric } \\
\text { artery }\end{array}$ & 0 & 4 & 6 & 10 \\
\hline Coeliac trunk & $\begin{array}{c}\text { 3 including } \\
\text { 1 reno-hepatic } \\
\text { 2 ilio-hepatic }\end{array}$ & 3 & 4 & 10 \\
\hline Total & 14 & 12 & 11 & 37
\end{tabular}


Table 3. Indications for renal/visceral bypass and type of revascularization.

Target vessel Indication (n)

Steep anteroposterior course and tight stenosis $(2)$

Early bifurcation (4)

Renal artery

Polar artery (2)

Takeoff in false lumen (1)

Tight angulation of aorta at the level of renal arteries (2)

\section{Type of revascularisation (n)}

Right hepato-renal prosthetic bypass $(1)^{S K}$

(2) Right ilio-renal and hepatic prosthetic bypass (1)

Bilateral right ilio-renal prosthetic bypass $(1)^{\dagger}$

Right hepato-renal prosthetic bypass (1)

Right ilio-renal and hepatic saphenous vein bypass (1)

Bilateral right ilio-renal prosthetic bypass $(1)^{\S}$

Bilateral right ilio-renal prosthetic bypass $(1)^{\dagger}$

Right hepato-renal saphenous vein bypass (1) ${ }^{S K}$

Right hepato-renal prosthetic bypass (1)

Left ilio-renal prosthetic bypass (1) ${ }^{S K}$

Bilateral right ilio-renal prosthetic bypass $(1)^{\S}$

Right reno-hepatic saphenous vein bypass (1)

Coeliac trunk Tight stenosis (3)

Right ilio-renal and hepatic saphenous vein bypass (1)

Right ilio-renal and hepatic prosthetic bypass (1)

${ }^{*},{ }^{\dagger},{ }^{\ddagger},{ }^{\S}$ indicate procedures performed in the same patient

$S K$ indicates patients with solitary kidney 